\title{
PERBANDINGAN KEBIJAKAN PERLUASAN KESEMPATAN KERJA DI INDIA DAN DI INDONESIA (STUDI KASUS : KABUPATEN SUMEDANG )
}

\author{
Friska Prastya Harlis ${ }^{1}$, Mohammad Benny Alexandri² \\ Program Pasca Sarjana Kebijakan Publik \\ Fakultas Ilmu Sosial dan Ilmu Politik \\ Universitas Padjadjaran
}

friska.p.h@gmail.com, mohammad.benny@unpad.ac.id²

\begin{abstract}
ABSTRAK
Negara India merupakan urutan kedua dengan jumlah penduduk terbanyak di Asia dan Indonesia merupakan negara ketiga terbanyak di Asia. Dilihat dari tingkat pengangguran negara India berada di posisi 30 dan negara Indonesia berada di urutan ke 18 di Asia. Dengan perbandingan jumlah penduduk yang cukup banyak negara India relatif memiliki tingkat pengangguran lebih rendah daripada negara Indonesia. Kebijakan Perluasan Kesempatan Kerja dapat mengatasi permasalahan pengangguran. Tujuan penelitian ini untuk menggambarkan bagaimana perbandingan Kebijakan Perluasan Kesempatan Kerja di India dan di Kabupaten Sumedang. Metodologi yang digunakan menggunakan analisis dengan data sekunder. Hasil penelitian menunjukkan Kebijakan Perluasan Kesempatan Kerja di India melalui Kebijakan Jaminan Ketenagakerjaan Pedesaan Nasional (MGNREGA) merupakan kebijakan inovatif yang dilakukan pemerintah India. Memiliki beberapa dampak yang positif antara lain meningkatkan upah pedesaan, mengurangi kesenjangan upah gender, meratakan dan menstabilkan konsumsi orang miskin, peningkatan dalam gizi, kesehatan dan pendidikan, peningkatan inklusi keuangan dan mengurangi migrasi. Sedangkan di Kabupaten Sumedang Kebijakan Perluasan Kesempatan Kerja mengacu pada tiga pilar utama yakni pelatihan, sertifikasi dan penempatan. Melalui beberapa program pelatihan dan terselenggaranya kegiatan Job Fair yang dilaksanakan di Kabupaten Sumedang belum dapat memberikan dampak yang positif dilihat dari jumlah angka pengangguran di Kabupaten Sumedang.
\end{abstract}

Kata Kunci: Pengangguran, Kebijakan Perluasan Kesempatan Kerja, India, Indonesia

\begin{abstract}
India is the second country with the largest population in Asia and Indonesia is the third largest country in Asia. Judging from the unemployment rate, India is in position 30 and Indonesia is ranked 18th in Asia. With a comparative population that is quite a lot of Indian countries relatively have a lower unemployment rate than Indonesia. The policy of expanding employment opportunities can overcome the problem of unemployment. The purpose of this study is to illustrate how the comparison of Employment Opportunity Policies in India and in Sumedang Regency. The methodology used uses analysis with secondary data. The results of the study show that the Policy for Extending Employment Opportunities in India through the National Rural Employment Guarantee Policy (MGNREGA) is an innovative policy carried out by the Indian government. Having a number of positive impacts include increasing rural wages, reducing the gender wage gap, leveling and stabilizing the consumption of the poor, improvements in nutrition, health and education, increasing financial inclusion and reducing migration. Whereas in Sumedang District the Employment Opportunity Policy refers to three main pillars, namely training, certification and placement. Through several training programs and the implementation of Job Fair activities held in Sumedang Regency, it has not been able to have a positive impact in terms of the number of unemployed people in Sumedang Regency.
\end{abstract}

Keywords: Unemployment, Employment Opportunity Expansion Policy, India, Indonesia

\section{PENDAHULUAN}

Kebijakan ketenagakerjaan merupakan hal yang penting untuk dibuat dan diterapkan. Mengingat permasalahan pengangguran yang sampai saat ini masih belum dapat diberantas di belahan negara manapun. Setiap tahun pemerintah selalu mengupayakan 


\section{Perbandingan Kebijakan Perluasan Kesempatan Kerja Di India Dan Di Indonesia \\ (Studi Kasus : Kabupaten Sumedang ) \\ (Friska Prastya Harlis, Mohammad Benny Alexandri)}

memininamalisir jumlah pengangguran yang ada di negaranya. Tingkat pengangguran yang tinggi dapat berdampak terhadap kesejahteraan warga negara, dengan adanya tingkat pengangguran yang tinggi mengakibatkan maraknya kejahatan-kejahatan sosial, kemiskinan dan kondisi ekonomi suatu negara tidak stabil. Berdasarkan data trandingeconomics.com negara Kongo berada di posisi tertinggi tingkat pengangguran di dunia dimana 46,1 \% dari total populasi penduduknya. Dan negara yang terendah tingkat penganggurannya berada di Qatar dengan 0,10 \% dari total populasi penduduknya. Sedangkan Indonesia sendiri menempati peringkat ke 105 di dunia dengan tingkat pengangguran $5.5 \%$ dari total populasi penduduk.

Berbeda halnya lagi jika di Asia, Indonesia berada di posisi ke 18 dari jumlah penduduk 255.461.700 jiwa. Indonesia merupakan negara ketiga yang memiliki jumlah penduduk terbanyak di Asia. Di urutan kedua ada negara India dengan jumlah 1.274.590.000 jiwa. Namun jika dilihat dari tingkat pengangguran negara India berada di posisi ke $30 \mathrm{di}$ Asia. Melihat kondisi ini pemerintah Indonesia harus berupaya lebih keras lagi agar dapat menekan tingkat pengangguran di Indonesia. Negara India saja yang mempunyai jumlah penduduk yang padat bisa berada di posisi yang cukup jauh dengan Indonesia.

Pengangguran terjadi karena adanya penambahan angkatan kerja dengan penambahan lapangan kerja tidak sebanding. Semakin bertambah banyak jumlah angkatan kerja dan semakin sedikit ketersediaan lapangan kerja maka menimbulkan ketimpangan yang cukup tinggi antara angkatan kerja dengan kesempatan kerja. Di Indonesia, permasalahan ketenagakerjaan ini diatur di dalam Undang-Undang Nomor 13 Tahun 2003 dimana di dalam pasal 39 sampai pasal 41 menjelaskan tentang perluasan kesempatan kerja. Kemudian dengan khusus melalui Peraturan Pemerintah Nomor 33 Tahun 2013 kebijakan perluasan kesempatan kerja ini diatur.

Tujuan artikel ini untuk menggambarkan bagaimana perbedaan kebijakan perluasan kesempatan kerja yang ada di India dengan yang ada di Indonesia dengan studi kasus di Kabupaten Sumedang. Dengan metode analisis agar dapat menggambarkan secara jelas bagaimana perbedaan kebijakan perluasan kesempatan kerja yang dilaksanakan di India dengan di Indonesia. Adapun struktur penulisan artikel ini terdiri dari pendahuluan, metodologi penelitian, hasil dan pembahasan, kesimpulan dan daftar pustaka.

\section{METODOLOGI PENELITIAN}

Metodologi penelitian yang dilakukan adalah metode analisis agar dapat menjelaskan bagaimana perbandingan kebijakan perluasan kesempatan kerja yang ada di India dengan yang ada di Indonesia (Studi Kasus Kabupaten Sumedang). Sumber data dalam penelitian ini menggunakan data sekunder yang berasal dari Peraturan, Penelitian Terdahulu (Jurnal) dan dari Internet.

\section{HASIL DAN PEMBAHASAN}

Negara India dan Negara Indonesia sama-sama merupakan kawasan Asia. Dan negara India dan Negara Indonesia merupakan negara berkembang. Negara India merupakan negara kedua yang memiliki jumlah penduduk banyak di dunia. Tercatat ada 1.281.935.911 jiwa atau sekitar 17,3\% dari jumlah penduduk di dunia. Sedangkan negara Indonesia menempati posisi keempat dengan jumlah penduduk 260.580.739 atau sekitar 3.5\% dari jumlah populasi penduduk di dunia. Melihat kondisi jumlah penduduk ini secara logika pasti akan sulit bagi negara India mensejahterakan warga negaranya daripada negara Indonesia. Namun, pada kenyataannya negara India memiliki jumlah tingkat pengangguran relatif lebih rendah daripada negara Indonesia.

Dilansir dari trandingeconomics.com tingkat pengangguran negara India berada di urutan ke 30 dari 43 negara di benua Asia. Sedangkan negara Indonesia berada di urutan ke 18. Melihat situasi ini cukup jauh perbedaan tingkat pengangguran di negara India dan negara Indonesia. Dengan jumlah penduduk yang berbeda jauh dengan negara Indonesia, negara India ini dapat meminimalisir tingkat pengangguran dari tahun ke tahun.

Sistem pemerintahan negara India merupakan sistem pemerintahan parlementer, dengan Presiden sebagai Kepala Negara dan Perdana Menteri sebagai kepala pemerintahan. Perdana Menteri diangkat oleh Parlemen dan Presiden diangkat melalui pemilihan umum. Berbagai upaya telah dilakukan oleh pemerintah India untuk mengentas pengangguran. Salah satunya melalui Undang-Undang Jaminan Ketenagakerjaan Pedesaan Mahatma Gandhi Nasional Rural Employment (MGNREGA) yang ditetapkan pada tanggal 7 September 2005. Tujuan dari ditetapkannya Undang-Undang MGNREGA ini adalah menyediakan lapangan kerja dengan skema kesejahteraan masyarakat desa dan untuk menghasilkan lebih banyak pertumbuhan ekonomi di pedesaan. Dengan menyediakan upah untuk 100 hari kerja dalam satu tahun untuk setiap rumah tangga dimana anggota dewasa melakukan pekerjaan berupa membangun prasarana desa seperti jalan desa dan saluran irigasi di pedesaan.

Samik Shome (2011) Jaminan Ketenagakerjaan Pedesaan Nasional (MGNREGA) merupakan sebuah program kreatif yang dilaksanakan oleh pemerintah India. Hal ini dianggap sebagai keputusan kebijakan penting oleh pemerintah India untuk memperbaiki situasi pengangguran pedesaan dengan penciptaan aset di pedesaan. Kebijakan Jaminan Ketenagakerjaan Pedesaan Nasional (MGNREGA) ini merupakan desain kebijakan inovatif. Adapun desain 
Kebijakan Jaminan Ketenagakerjaan Pedesaan Nasional

(MGNREGA) sebagai berikut :

\section{GAMBAR I}

\section{KEBIJAKAN JAMINAN KETENAGAKERJAAN PEDESAAN NASIONAL (MGNREGA) DI INDIA}

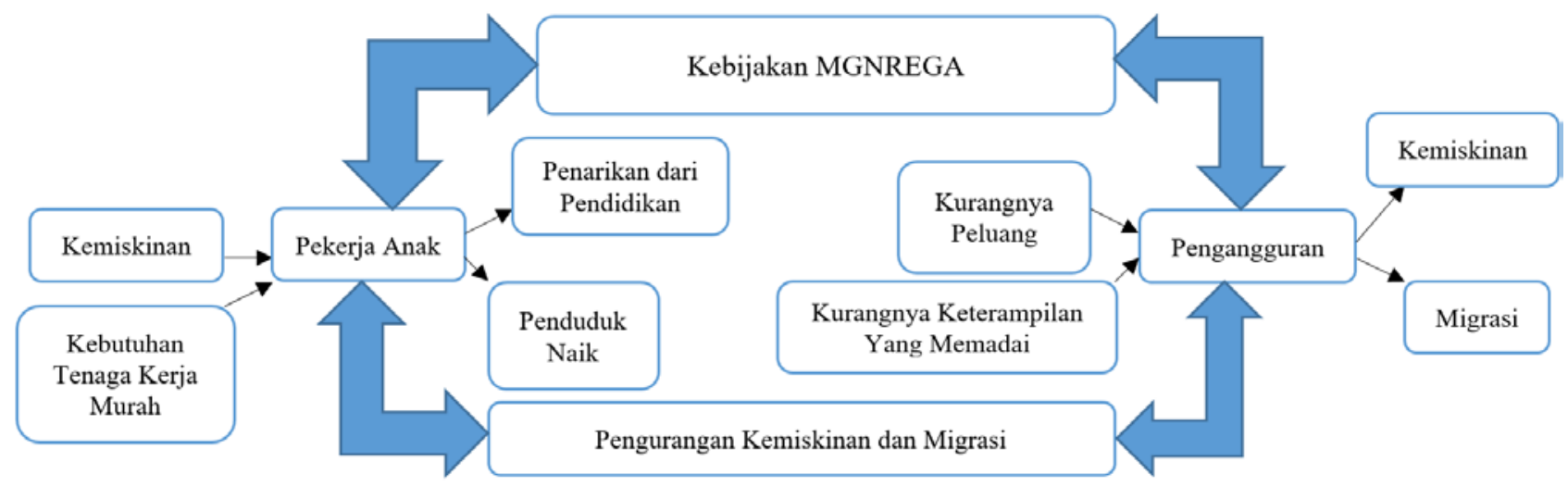

Sumber : Samik Shome (2011) dalam jurnal “Techniques in Innovative Policy Making: Example of National Rural Employment Guarantee Act in India”

Jika kita lihat desain Kebijakan Jaminan Ketenagakerjaan Pedesaan Nasional (MGNREGA) di atas, munculnya Undang-Undang Jaminan Ketenagakerjaan Pedesaan Mahatma Gandhi Nasional Rural Employment (MGNREGA) pada tahun 2005 karena ada dua permasalahan di India, yakni pekerja anak dan pengangguran. Dimana faktor yang mempengaruhi adanya permasalahan pekerja anak adalah kemiskinan dan kebutuhan tenaga kerja yang murah. Munculnya pekerja anak mengakibatkan penarikan dari pendidikan, banyaknya anak di bawah umur bekerja sehingga tidak bersekolah dan jumlah penduduk naik karena bertambah terus jumlah angka kelahiran yang menurut masyarakat negara India itu bukanlah suatu permasalahan karena seorang anak dapat dipekerjakan dengan mudah. Lalu permasalahan kedua di India mengenai pengangguran, faktor yang mempengaruhi hadirnya pengangguran karena kurangnya kesempatan kerja yang ada di India dan kurangnya keterampilan yang dimiliki oleh individu. Masalah pengangguran ini berdampak pada kemiskinan dan migrasi. Banyaknya dorongan dari desa agar masyarakat desa melakukan migrasi ke kota. Dengan kata lain Kebijakan Jaminan Ketenagakerjaan Pedesaan (MGNREGA) ini bertujuan untuk mengatasi segala permasalahan yang berkaitan dengan pekerja anak dan pengangguran dengan tujuan untuk mengurangi kemiskinan dan migrasi yang terjadi di India.

Kebijakan Jaminan Ketenagakerjaan Pedesaan (MGNREGA) memiliki beberapa dampak yang positif, antara lain meningkatkan upah pedesaan, mengurangi kesenjangan upah gender, meratakan dan menstabilkan konsumsi orang miskin, peningkatan dalam gizi, kesehatan dan pendidikan, peningkatan inklusi keuangan dan mengurangi migrasi. Bahkan di beberapa daerah di India telah membantu meningkatkan konektivitas pedesaan dan produktivitas pertanian dengan menciptakan bentuk irigasi dan produksi yang lebih berkelanjutan (S. Mahendra Dev, 2018).

Diberlakukannya Kebijakan Jaminan Ketenagakerjaan Pedesaan (MGNREGA) di India membawa negara India tingkat pengangguran di urutan ke 30 di Asia. Lalu bagaimana kebijakan perluasan kesempatan kerja di negara kita sendiri ?

Berdasarkan data Badan Pusat Statistik (BPS) di tahun 2018 di Indonesia mengalami penurunan sebanyak 140 ribu orang dari jumlah pengangguran pada tahun sebelumnya. Hal ini sejalan dengan penurunan angka Tingkat Pengangguran Terbuka (TPT) dari 5,61\% menjadi 5,50\%. Tingkat Pengangguran Terbuka (TPT) merupakan persentase jumlah pengangguran yang termasuk dalam penduduk usia kerja terhadap jumlah angkatan kerja. Dilihat dari tingkat pendidikan, Tingkat Pengangguran Terbuka (TPT) untuk Sekolah Menengah Kejuruan (SMK) tertinggi diantara tingkat pendidikan lain, yaitu sebesar $8,92 \%$.

Adanya penurunan ini tidak memberikan dampak yang signifkan terhadap kesejahteraan masyarakat. Pengangguran di Indonesia masih menjadi masalah sosial dalam pembangunan kehidupan masyarakat Indonesia. Masalah pengangguran merupakan keadaan terkendalanya pemenuhan hak atas kesejahteraan dan hak atas pekerjaan.

Terlihat di dalam data Badan Pusat Statistik (BPS) bahwa Tingkat Pengangguran Terbuka (TPT) terbanyak berada di Jawa Barat, yang berada di angka 8,16\%. Di posisi kedua dan ketiga ada Banten di angka 


\section{Perbandingan Kebijakan Perluasan Kesempatan Kerja Di India Dan Di Indonesia \\ (Studi Kasus : Kabupaten Sumedang ) \\ (Friska Prastya Harlis, Mohammad Benny Alexandri)}

7,72\% dan Maluku di angka 7,38\%. Persentase pengangguran paling rendah berada di Bali dengan 0,86\%, Sulawesi Barat dengan 2,45\%, dan Bengkulu dengan $2,70 \%$.

Dilihat dari data tersebut Tingkat Pengangguran Terbuka (TPT) Provinsi Jawa Barat berada di posisi teratas. Misalnya saja di Kabupaten Sumedang, dengan tingkat pengangguran yang besar, Kabupaten Sumedang menghasilkan jumlah angkatan kerja yang hanya sedikit tiap tahunnya. Tercatat bahwa jumlah pengangguran di Kabupaten Sumedang mencapai 50 ribu orang pada tahun 2018. Angka itu sekitar 9\% dari jumlah penduduk di Kabupaten Sumedang. Hal ini berarti upaya pengentasan pengangguran yang dilakukan oleh pemerintah di Kabupaten Sumedang masih belum berarti apa-apa.

Kebijakan perluasan kesempatan kerja di Indonesia dituangkan di dalam peraturan-peraturan tentang ketenagakerjaan. Untuk lebih jelasnya dapat dilihat gambar di bawah ini :

\section{GAMBAR II \\ KEBIJAKAN PERLUASAN KESEMPATAN KERJA DI INDONESIA}

Undang-Undang Dasar 1945

Undang-Undang Nomor 13 Tahun 2003 tentang Ketenagakerjaan
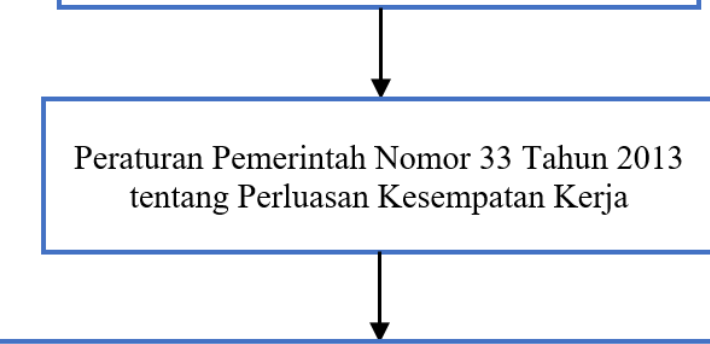

Peraturan Bupati Sumedang Nomor 11 Tahun 2017 tentang Uraian Tugas Jabatan Struktural Pada Dinas Tenaga Kerja dan Transmigrasi

Sumber : Hasil Analisis Penulis (2018)

Di dalam Undang-Undang Dasar 1945, pasal 27 ayat 2 menyebutkan bahwa "Tiap-tiap warga negara berhak atas pekerjaan dan penghidupan yang layak bagi kemanusiaan. Dengan demikian, adanya pengakuan dan jaminan bagi semua masyarakat Indonesia untuk mendapatkan pekerjaan dan mencapai tingkat kehidupan yang layak bagi kemanusiaan. Dari pasal yang terkandung di dalam Undang-Undang Dasar 1945 terbitlah suatu Undang-Undang yang mengatur hal tersebut melalui Undang-Undang Nomor 13 Tahun 2003 tentang Ketenagakerjaan. Undang-Undang ini merupakan payung bagi peraturan ketenagakerjaan lainnya. Karena Undang-Undang Nomor 13 Tahun 2003 menggantikan 15 peraturan ketenagakerjaan yang pernah berlaku sebelumnya. Undang-Undang Nomor 13 Tahun 2003 ini berisikan tentang tenaga kerja, peluang dan kesempatan kerja, pelatihan kerja, penempatan tenaga kerja, penggunaan tenaga kerja asing (TKA), hubungan kerja serta pemutusan hubunan kerja (PHK).

Adapun secara rinci mengenai perluasan kesempatan kerja dijelaskan pada pasal 40 ayat 2 yang berbunyi "Penciptaan perluasan kesempatan kerja sebagaimana dimaksud dalam ayat (1) dilakukan dengan pola pembentukan dan pembinaan tenaga kerja mandiri, penerapan sistem padat karya, penerapan teknologi tepat guna, dan pendayagunaan tenaga kerja sukarela atau pola lain yang dapat mendorong terciptanya perluasan kesempatan kerja”. Hal ini berarti untuk memaksimalkan perluasan kesempatan kerja di Indonesia pemerintah dapat melaksanakan programprogram yang berkaitan dengan kebijakan yang telah diatur di dalam pasal tersebut.

Dan untuk melaksanakan ketentuan perluasan kesempatan kerja keluarlah sebuah Peraturan Pemerintah Nomor 33 Tahun 2013 Tentang Perluasan Kesempatan Kerja. Dimana di dalam Peraturan Pemerintah ini lebih spesifik tentang perluasan kesempatan kerja. Di dalam Peraturan Pemerintah Nomor 33 Tahun 2013 Pasal 9 disebutkan bahwa "Pemerintah dan Pemerintah Daerah memfasilitasi pelaksanaan pola sebagaimana dimaksud dalam Pasal 8 melalui kegiatan:

(a) permodalan;

(b) penjaminan;

(c) pendampingan;

(d) pelatihan;

(e) konsultasi;

(f) bimbingan teknis; dan/atau

(g) penyediaan data dan informasi.”

Untuk mendukung pelaksanakan Peraturan Pemerintah Nomor 33 Tahun 2013 tentang Perluasan Kesempatan Kerja pemerintah daerah Kabupaten Sumedang mengeluarkan kebijakan yang tertuang pada Peraturan Bupati Sumedang Nomor 11 Tahun 2017 Tentang Uraian Tugas Jabatan Struktural Pada Dinas Tenaga Kerja dan Transmigrasi. Dinas Tenaga Kerja dan Transmigrasi merupakan salah satu pihak yang bertanggung jawab dalam melaksanakan urusan pemerintahan dalam rangka pelaksanaan sebagian tugas Bupati khususnya di bidang ketenagakerjaan dan transmigrasi. Tugas pokok dinas ini adalah membuat kebijakan untuk mengatasi masalah kesempatan kerja.

Sampai sejauh ini pemerintah Kabupaten Sumedang melalui Dinas Tenaga Kerja dan 
Transmigrasi telah melakukan beberapa kegiatan dari kebijakan perluasan kesempatan kerja yang telah tertuang di dalam Undang-Undang Nomor 13 Tahun 2003, di antaranya menciptakan wirausaha baru dengan memberikan program pelatihan untuk meningkatkan keterampilan, keahlian, managemen, dan administrasi serta pembekalan peserta wirausaha baru tenaga kerja mandiri dengan pola pendampingan bagi orang tua pekerja anak pada Lembaga Pemerintah dan Non Pemerintah.

Namun, program yang dilaksanakan oleh pemerintah Kabupaten Sumedang ini belum dapat menekan jumlah pengangguran di Kabupaten Sumedang. Mardianta (2001) menunjukkan bahwa kegiatan ekonomi seperti kegiatan penyerapan tenaga kerja lebih banyak dilakukan oleh pendatang daripada penduduk lokal. Sehingga adanya program pelatihan bagi warga Kabupaten Sumedang dipat dikatakan belum dapat menghasilkan apa-apa. Karena warga pendatang lebih mendominasi daripada warga masyarakat Kabupaten Sumedang itu sendiri.

Dalam melaksanakan kebijakan perluasan kesempatan kerja Dinas Tenaga Kerja dan Transmigrasi berpedoman pada tiga pilar utama yaitu pelatihan, sertifikasi dan penempatan. Selain program pelatihan adapun yang dilakukan oleh pemerintah Kabupaten Sumedang ini melalui penempatan. Melalui penyelenggaraan Job Fair, diharapkan dapat mempermudah perluasan kesempatan kerja dengan mempertemukan pencari kerja dengan pengguna kerja. Dengan adanya Job Fair ini pemerintah telah memfasilitasi pencari kerja sehingga mendapatkan pekerjaan sesuai dengan bakat, minat dan kemampuan yang dimiliki. Namun penyelenggaraan Job Fair ini juga dilaksanakan dengan belum optimal tidak ada rentan waktu rutin untuk terselenggaranya Job Fair.

\section{KESIMPULAN}

Kebijakan Perluasan Kesempatan Kerja sangat penting untuk mengatasi permasalahan pengangguran di berbagai negara. Seperti yang terjadi di negara India melalui Kebijakan Jaminan Ketenagakerjaan Pedesaan Nasional (MGNREGA) dengan tujuan untuk menyediakan lapangan kerja dengan skema kesejahteraan masyarakat desa dan untuk menghasilkan lebih banyak pertumbuhan ekonomi di pedesaan. Kebijakan inovatif ini memberikan dampak yang positif dengan menarik masyarakat desa di India agar tidak terdorong keluar untuk mencari pekerjaan. Dengan mengoptimalkan segala sumber daya yang ada di pedesaan India. Berbeda halnya di Indonesia, melalui studi kasus di Kabupaten Sumedang Kebijakan Perluasan Kesempatan Kerja mengacu pada tiga pilar utama yakni pelatihan, sertifikasi dan penempatan. Melalui beberapa program pelatihan dan terselenggaranya kegiatan Job Fair yang dilaksanakan di Kabupaten Sumedang belum dapat menekan angka pengangguran. Jika di negara India mengeluarkan suatu kebijakan perluasan kesempatan kerja dengan meningkatkan aset di pedesaan berbeda dengan di Indonesia (studi kasus di Kabupaten Sumedang) lebih menekankan pada kualitas sumber daya manusia Kabupaten Sumedang.

\section{SARAN}

Melihat Kebijakan Jaminan Ketenagakerjaan Pedesaan Nasional (MGNREGA) di India yang berhasil dengan mendorong pertumbuhan ekonomi di pedesaan dengan mengoptimalkan segala sumber daya di pedesaan, pemerintah Indonesia dapat menerapkan kebijakan tersebut di wilayah-wilayah Indonesia. Agar tidak ada kesenjangan antara kota dan desa. Pemerintah dapat mendorong pertumbuhan lapangan kerja di desa, salah satunya di Kabupaten Sumedang. Dengan mengeluarkan kebijakan yang bersifat mendorong pertumbuhan perekenomian desa, baik dengan program tumbuhnya usaha-usaha mandiri di Kabupaten Sumedang ataupun dengan mengoptimalkan kegiatan pertanian karena tercatat bahwa 52,88\% merupakan lahan pertanian di Kabupaten Sumedang.

\section{DAFTAR PUSTAKA}

\section{Peraturan}

Undang-Undang Dasar 1945

Undang-Undang Nomor 13 Tahun 2003 Tentang Ketenagakerjaan

Peraturan Pemerintah Nomor 33 Tahun 2013 Tentang Perluasan Kesempatan Kerja

Peraturan Bupati Sumedang Nomor 11 Tahun 2017 tentang Uraian Tugas Jabatan Struktural Pada Dinas Tenaga Kerja dan Transmigrasi

\section{Jurnal}

Al-Enezi, Awadh, Khalaf 2014, 'Kuwait’s Employment Policy: Its Formulation, Implications, and Challenges', International Journal of Public Administration, Vol. 25, No. 7, hh. 885-900.

Bellair, Paul, E., \& Kowalski, Brian, R 2011 'Low-Skill Employment Opportunity and African American-White Difference in Recidivism', Journal of Research in Crime and Delinquency, Vol. 48, No. 2, hh. 176-208.

Ghose, Ajit, K 2016, 'Globalization, Growth and Employment in India', Indian Journal of Human Development, Vol. 10, No. 2, hh. 127156. 


\section{Perbandingan Kebijakan Perluasan Kesempatan Kerja Di India Dan Di Indonesia \\ (Studi Kasus : Kabupaten Sumedang ) \\ (Friska Prastya Harlis, Mohammad Benny Alexandri)}

Islam, Iyanatul 2018, 'Automation and the Future of Employment: Implications for India', South Asian Journal of Human Resources Management, hh. 1-10.

Mahendra, S, Dev 2018, 'Labour Market Inequalities in India: Dimensions and Policies', Indian Journal of Human Development, Vol. 12, No. 2, hh. 1-19.

Maiorano, Diego., Bjokert, Suruchi, Tapar., \& Blomkvist, Hans 2016, 'The paradoxes of empowerment: gendering NREGA in the rural landscape of India', Development in Practice, Vol. 26, No. 1, hh. 127-134.

Mason, Susan, G 2008, 'Regional Cooperation in Employment and Training Policy: A Matter of Collective Action or Intergovernmental Relations?', Community Development, Vol. 39, No. 4, hh. 1-16.

Orife, John, N., \& Chaubey, Manmohan, D 2008, 'Models of Equal Employment Opportunity', Journal of African Business, Vol. 2, No.3, hh. 93-113.

Pedace, Roberto., \& Dubois, Christine 2012, 'Immigration policy and employment assimilation in the United States', Applied Economics, Vol. 44, No. 36, hh. 4721-4730.

Peetz, David., Gardner, Margaret., Brown, Kerry., \& Berns, Sandra 2008, 'Workplace effects of equal employment opportunity legislation: the Australian experience', Policy Studies, Vol. 29, No. 4, hh. 405-419.

Reddy, D, Narasimha 2013, 'Formal Credit and Rural Occupational Diversification: Recent Experience in India', Journal of Land and Rural Studies, Vol. 1, No. 1, hh. 1-24.

Running, Katherine 2015, 'The liberalisation of India's labour laws within the National Manufacturing Policy 2011: where business power and social policy collide', Journal of International and Comparative Social Policy, Vol. 31, No. 2, hh. 192:208.

Sharma, Pankaj., Nookala, Srinivasa, B, S., \& Sharma, Anubhav 2012, 'India's National and Regional Innovation Systems: Challenges, Opportunities and Recommendations for Policy Makers', Industry and Innovation, Vol. 19, No. 6, hh. 517-537.

Shome, Samik 2011, 'Techniques in Innovative Policy Making: Example of National Rural Employment Guarantee Act in India', International Journal of Public Administration, Vol. 34, No. 5, hh. 267-278.
Singh, Jitender., \& Mitra, Arup, 'Regulation and employment: assessing wage elasticity in Indian manufacturing', Labour \& Industry: a journal of the social and economic relations of work, Vol. 27, No. 1, hh. 1-18.

\section{Internet}

https://id.tradingeconomics.com/countrylist/unemployment-rate

https://ilmupengetahuanumum.com/10-negara-denganjumlah-penduduk-populasi-terbanyak-didunia/

https://www.theguardian.com/globaldevelopment/2015/feb/05/india-ruralemployment-funding-cuts-mgnrega

https://www.bps.go.id/pressrelease/2018/05/07/1484/fe bruari-2018--tingkat-pengangguran-terbuka-tpt--sebesar-5-13-persen--rata-rata-upahburuh-per-bulan-sebesar-2-65-jutarupiah.html

https://glints.com/id/lowongan/fakta-pengangguranindonesia/

https://sumedangkab.bps.go.id/statictable.html

http://www.pikiran-rakyat.com/jawabarat/2017/03/20/peluang-kerja-di-industrisumedang-lebih-banyak-untuk-sarjana-teknik396789

https://www.sumedang.online/2018/10/disnakertranssumedang-bidik-ciptakan-wub-tenaga-kerjamandiri/

https://www.kompasiana.com/sastra123/5bbc8000677f fb351c78dd55/disnaker-sumedang-siapkantenaga-kerja-mandiri

http://jabarprov.go.id/index.php/news/25788/2017/11/1 1/45-Ribu-Penduduk-Sumedang-Nganggur 